\title{
A NEW ESTIMATE OF THE DIFFERENCE AMONG QUASI-ARITHMETIC MEANS
}

\author{
PAWEŁ PASTECZKA
}

Abstract. In the 1960s Cargo and Shisha proved some majorizations for the distance among quasi-arithmetic means (defined as $f^{-1}\left(\sum_{i=1}^{n} w_{i} f\left(a_{i}\right)\right)$ for any continuous, strictly monotone function $f: I \rightarrow \mathbb{R}$, where $I$ is an interval, and $\left(a_{1}, \ldots, a_{n}\right)$ is a vector with entries in $I$, $\left(w_{1}, \ldots, w_{n}\right)$ is a sequence of corresponding weights $\left.w_{i}>0, \sum w_{i}=1\right)$.

Nearly thirty years later, in 1991, Páles presented an iff condition for a sequence of quasi-arithmetic means to converge to another QA mean. It was closely related with the threeparameter operator $(f(x)-f(y)) /(f(x)-f(z))$.

The author presented recently an estimate for the distance among such quasi-arithmetic means whose underlying functions satisfy some smoothness conditions. Used was the operator $f \mapsto f^{\prime \prime} / f^{\prime}$ introduced in the 1940 s by Mikusiński and Łojasiewicz. It is natural to look for similar estimate(s) in the case of the underlying functions not being smooth. For instance, by the way of using Páles' operator. This is done in the present note. Moreover, the result strengthens author's earlier estimates.

Mathematics subject classification (2010): 26E60, 26D15, 26D07.

Keywords and phrases: Quasi-arithmetic means, metric, Arrow-Pratt index.

\section{REFERENCES}

[1] G. T. Cargo And O. Shisha, On comparable means, Pacific J. Math. 14 (3), 1964, 1053-1058.

[2] G. T. CARGo AND O. Shisha, A metric space connected with generalized means, J. Approx. Theory $2(2), 1969,207-222$.

[3] B. DE FinetTi, Sul concetto di media, G. Ist. It. Att. 2 (3), 1931, 369-396.

[4] A. Kolmogoroff, Sur la notion de la moyenne, Rend. Accad. dei Lincei 12 (6), 1930, 388-391.

[5] J. G. Mikusińs KI, Sur les moyennes de la forme $\psi^{-1}\left[\sum q \psi(x)\right]$, Studia Math. 10 (1), 1948, 90-96.

[6] M. Nagumo, Über eine Klasse der Mittelwerte, Japan. J. Math. 7 (1), 1930, 71-79.

[7] M. Nos ARZEWSKa, On uniform convergence in some classes of functions, Fund. Math. 39 (1), 1952, $38-52$.

[8] Zs. PÁLES, Report of Meeting 15th International Conference on Functional Equations and Inequalities, Ann. Univ. Paedagog. Crac. Stud. Math. XII (1), 2013, 121-122.

[9] Zs. PÁLES, On the convergence of Means, J. Math. Anal. Appl. 156 (1), 1991, 52-60.

[10] P. PasteczKa, When is a Family of Generalized Means a Scale?, Real Anal. Exchange 38 (1), 2013, 193-210.

[11] G. PólyA, Wohlbekannt ist folgender Satz von Dini, Arxiv der Mathematic und Phisik 28 (1), 1920, 174. 